\title{
The Potential Use of a Food-Dyeing Plant Peristrophe bivalvis (L.) Merr. in Northern Vietnam
}

\author{
Nguyen Van Quan ${ }^{1-2, a}$, Do Tan Khang ${ }^{1, b}$, Luan Thi Dep ${ }^{2, c}$, \\ Truong Ngoc Minh ${ }^{1, d}$, Nakagoshi Nobukazu ${ }^{1, e}$, and Tran Dang Xuan ${ }^{1, f^{*}}$ \\ ${ }^{1}$ Graduate School for International Development and Cooperation (IDEC), Hiroshima University, \\ Japan \\ ${ }^{2}$ Thai Nguyen University of Agriculture and Forestry, Vietnam \\ Email: anguyenquan26@gmail.com, bdtkhang@ctu.edu.vn, 9uanthidep@tuaf.edu.vn, \\ dminhtn689@gmail.com, ${ }^{\mathrm{e}}$ nobu@hiroshima-u.ac.jp, ${ }^{\mathrm{f}} \mathrm{tdxuan@hiroshima-u.ac.jp}$
}

Keywords: Peristrophe bivalvis, indigenous knowledge, phytochemicals, antioxidant capacity.

\begin{abstract}
An investigation on the current usage status and experience in using Peristrophe bivalvis (L.) Merr. was conducted in the mountainous region of Northern Vietnam. Five varieties were collected and recorded as a source of foodstuff-dyeing and medicinal plants on indigenous knowledge of ethnic minorities in the study area, of which, three varieties were dyed purple, one red and one yellow-orange; with two varieties being used for the treatment of haemoptysis, dysentery, liver disease, kidney failure, and jaundice. Two extraction methods using organic solvents and aqueous solvent were applied to spectrophotometrically investigate the phytochemical contents of Peristrophe bivalvis varieties. Accordingly, the coloration components of Peristrophe bivalvis varieties were contributed by a complex compound of photosynthetic pigments, anthocyanins, flavonoids. Also, the total phenolics, total flavonoids and effect of extraction methods, dissolved solutions (water and methanol) on these contents were assessed. Besides, screening antioxidant capacity of Peristrophe bivalvis varieties was assayed by 1,1-diphenyl-2-picrylhydrazyl (DPPH) method which showed stronger radical inhibition of organic extractions than that of aqueous extractions. The results of determination of phytochemicals and antioxidant capacity support the knowledge and experience in using Peristrophe bivalvis varieties as natural dyeing production for food and pharmaceutical industry.
\end{abstract}

\section{Introduction}

The utilization of plant for food dyeing is no longer a novelty in the world. In Vietnam, using plants in processing and coloring food has been a long-standing experience favoured among the ethnic minorities - especially those residing in the Northern mountainous regions. Among food-dyeing plants, Peristrophe bivalvis (L.) Merr. is the most commonly used and widely grown to make foods more attractive-looking. The traditional foods dyed with $P$. bivalvis are very diverse and pregnant with various cultural values, which vary by each ethnic group and each region. However, the investigations revolved around $P$. bivalvis scattered and systematically deficient in Vietnam, especially on the local experience in dyeing food, cultivation modality, and economic value. Moreover, the indigenous knowledge in using such plant for common life is genuinely important. Article 8 (j) of the Convention on Biological Diversity precisely manifested that the link between biodiversity and cultural diversity plays a key role to maintain the in-situ conservation [1]. Therefore, the research and proposing solutions seek to preserve experience in using $P$. bivalvis in Northern Vietnam is essential.

According to Vietnam Plant Data Center, Peristrophe bivalvis (L.) Merr. [Peristrophe roxburghiana (Schult.) Bremek.] is essentially a herbaceous perennial plant which distributes widely in cool and humid climate areas. Based on the different colors of extracts and morphological characteristics, P. bivalvis appears in four varieties which are purple, purple-magenta, red, and yellow $[2,3,4]$. The identification of these varieties primarily bases on the difference between their phenotypes, such as the leaf shape and difference among colorants extracted from them. Apart from 
decorating role in foodstuffs, $P$. bivalvis has many biological and pharmaceutical activities including the treatment of blood diseases, anti-hypertension, anti-hyperlipidemia, fungistatic and antibacterial properties [5-8]. Phaopongthai et al. [9] reported that $P$. bivalvis ethanolic extracts had the anti-snake venom activity against Naja kaouthia and Trimeresurus albolabris venoms. Another study highlighted the effectiveness of $P$. bivalvis ethanolic extracts on inhibition of bacteria consisting of Bacillus subtilis, Staphylococcus aureus, Escherichia coli, and Pseudomonas aeruginosa [10,11]. Thuy et al. showed the new application of $P$. bivalvis by evaluating the alkaloid components from purple and red varieties growing in Vietnam $[12,13]$.

Although there were some scientific achievements on studying Peristrophe bivalvis, the comprehensive studies on $P$. bivalvis are quite limited. What is concerning the researcher is that most of the studies have only focused on a certain variety or an unclear variety which probably cause inaccurate analysis results. Therefore, it is really important to clarify the existence and phytochemical properties of $P$. bivalvis varieties in the northern Vietnam. This study is conducted to achieve the objectives including investigating the presence and current usage of $P$. bivalvis varieties for dyeing food-stuffs of ethnic minorities in the northern mountainous region of Vietnam, determining the pigment components, total phenolic content, total flavonoid content, and antioxidant capacity of various $P$. bivalvis varieties cultivated in Northern Vietnam.

\section{Materials and methods}

\section{Plant materials}

Plant samples were collected on some criteria as intact, fresh, and without signs of pests. After washing and draining in the field, samples were wrapped up by paper bags. After that, the samples including leaves and stems were dried at $35^{\circ} \mathrm{C}$ for 10 days in the oven and ground, thereafter kept at $4^{\circ} \mathrm{C}$ in the fridge until use.

The identification of Peristrophe bivalvis was referred from Vietnam Plant Data Center (http://www.botanyvn.com) and Plants Database Missouri Botanical Garden, United States (TROPICOS - http://www.tropicos.org). Also, the differentiation of varieties was implemented by testing the color of hot water decoction from each adequate samples in the field.

The plants' seedlings have been cultivated and vouchers have been deposited in Thai Nguyen University of Agriculture and Forestry, Vietnam. Details of the plants are shown in Table 1.

\section{Field survey}

An ethnobotanical investigation was conducted on the current usage status and experience in using Peristrophe bivalvis for foodstuff dyeing and other purposes among ethnic minorities in the northern mountainous region of Vietnam, including Lai Chau, Bac Kan and Thai Nguyen Provinces. The interviews were built on a questionnaire mainly carried out among 140 households of the ethnic minorities by the main author from the beginning of August 2015 to the end of September 2015.

\section{Experimental survey}

\section{Plant extracts}

The plant extractions are as described in Figure 1. Five different samples were used in the extraction process by using organic solvents and an aqueous solvent (distilled water). The extracts were named as the corresponding solvent and methods used.

\section{Determination of Chlorophyll $a$, Chlorophyll $b$ and total carotenoids}

Photosynthetic pigment contents were determined according to Metzner, Rau, and Senger [14] and Fayez and Bazaid [15] with minor modification. The extraction method was unique to this experiment as follows: each dried ground sample $(100 \mathrm{mg})$ was extracted in $2 \mathrm{~mL}$ of $85 \%(\mathrm{v} / \mathrm{v})$ aqueous acetone. The mixture was vigorously shaken and centrifuged at $5000 \mathrm{rpm}$ for 5 mins. The supernatant was collected and then diluted by the extracting solvent to a suitable concentration for spectrophotometric measurement. The absorbance was measured against a blank of the extracting solvent at three wavelengths of 452, 644 and $663 \mathrm{~nm}$ by a HACH DR/4000U spectrophotometer. Total photosynthetic pigments were calculated using the following equations: 


$$
\begin{gathered}
\text { Chlorophyll } a(\mathrm{Chl} a)=10.3 \times \mathrm{A}_{663}-0: 918 \times \mathrm{A}_{644} \\
\text { Chlorophyll } b(\mathrm{Chl} b)=19.7 \times \mathrm{A}_{644}-3.87 \times \mathrm{A}_{663} \\
\text { Total carotenoids }=4.2 \times \mathrm{A}_{452}-((0.0264 \times \mathrm{Chl} a)+(0.426 \times \mathrm{Chl} b))
\end{gathered}
$$

where $A_{663}, A_{644}$, and $A_{452}$ are absorbance measured at 452, 644 and $663 \mathrm{~nm}$ respectively. The photosynthetic pigments were expressed as $\mathrm{mg} \mathrm{g}^{-1}$ dry weight (DW).

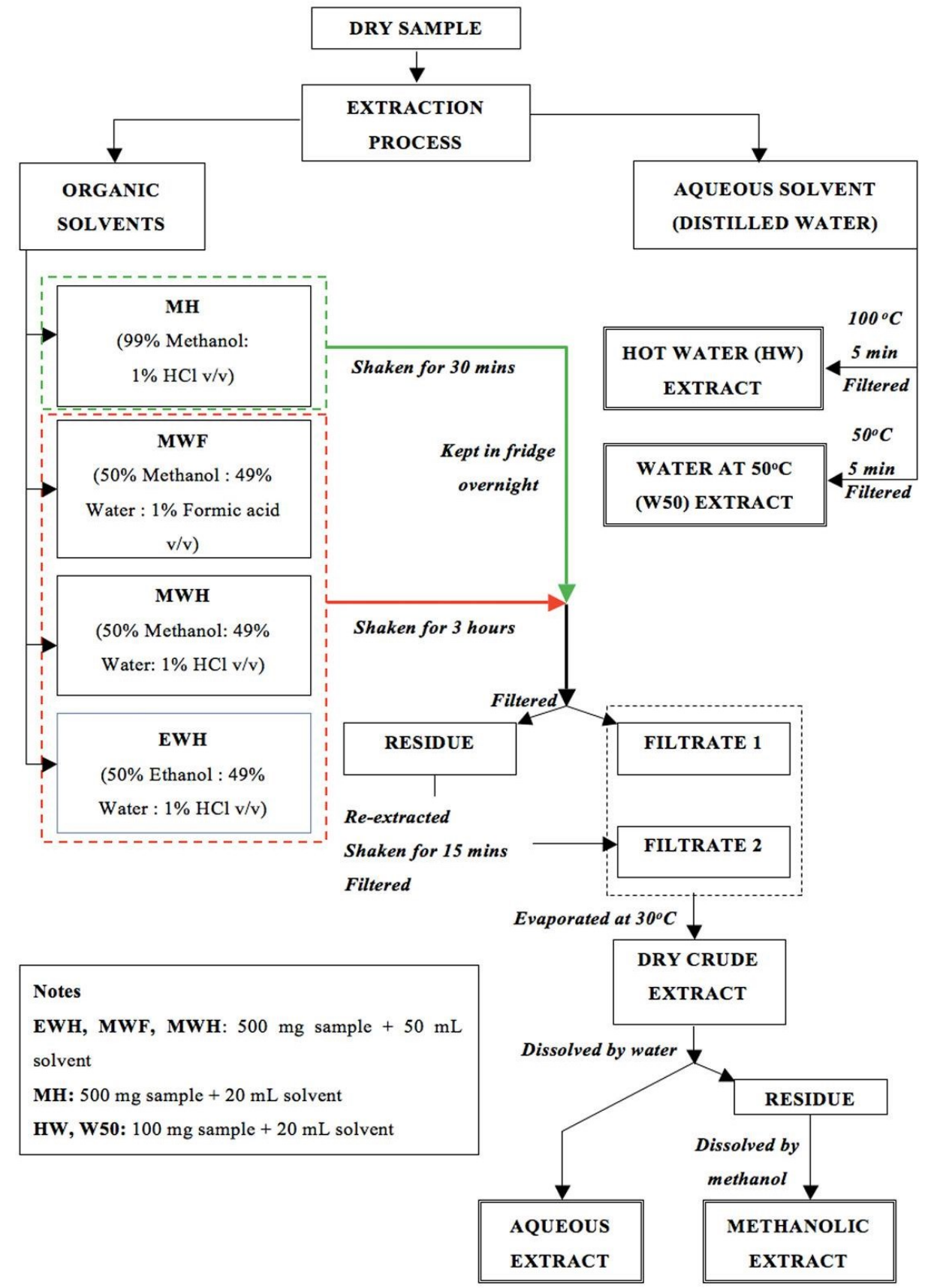

Fig. 1 The extraction process of Peristrophe bivalvis samples

\section{Determination of Total Anthocyanin Contents (TACs)}

Quantification of total anthocyanins in P. bivalvis was evaluated with the $\mathrm{pH}$ differential method which integrated both methods of Giusti, Rodriguez-Saona, and Wrolstad [16] and Lee, Durst, and Wrolstad [17] with minor modifications. Each extract was diluted in turn by $\mathrm{pH} 1.0$ buffer (potassium chloride, $0.025 \mathrm{M}$ ) and $\mathrm{pH} 4.5$ buffer (sodium acetate, $0.4 \mathrm{M}$ ) to an appropriate concentration for spectrophotometric measurement. Subsequently, the absorbance of five P.bivalvis samples was measured at $520 \mathrm{~nm}$ and $700 \mathrm{~nm}$ by a HACH DR/4000U spectrophotometer. Anthocyanin content was expressed as $\mathrm{mg}$ cyanidin-3-glucoside equivalents in $\mathrm{g}$ dry weight (mg $\mathrm{C} 3 \mathrm{GE} \mathrm{g}^{-1} \mathrm{DW}$ ), as follows: 


$$
\mathrm{TAC}=\left(\mathrm{A} \times \mathrm{MW} \times \mathrm{DF} \times 10^{3}\right): \varepsilon * 1
$$

where $\mathrm{A}=\left(\mathrm{A}_{520 \mathrm{~nm}}-\mathrm{A}_{700 \mathrm{~nm}}\right)_{\mathrm{pH} 1.0}-\left(\mathrm{A}_{520 \mathrm{~nm}}-\mathrm{A}_{700 \mathrm{~nm}}\right)_{\mathrm{pH} 4.5} ; \mathrm{MW}=449.2 \mathrm{~g} / \mathrm{mol}=$ molecular weight of cyanidin-3-glucoside (cyd-3-glu); $\mathrm{DF}=$ dilution factor; $1=$ pathlength in $\mathrm{cm} ; \varepsilon=26900=$ molar extinction coefficient of cyd-3-glu in $\mathrm{L} \mathrm{x} \mathrm{mol}^{-1} \mathrm{x} \mathrm{cm}^{-1}$; and $10^{3}=$ factor for conversion from $\mathrm{g}$ to $\mathrm{mg}$. TACs in the organic extraction was calculated by water-soluble anthocyanins plus methanol-soluble anthocyanins.

Determination of Total Phenolic Contents (TPCs)

Total phenolic content was calculated according to the Folin-Ciocalteu method described by Elzaawely et al. [18]. Concisely, $0.1 \mathrm{~mL}$ of extract was added in turn by $0.5 \mathrm{~mL}$ of $10 \%(\mathrm{v} / \mathrm{v})$ FolinCiocalteu's reagent and $0.4 \mathrm{~mL}$ of $7.5 \%$ (w/v) $\mathrm{Na}_{2} \mathrm{CO}_{3}$ in water. After 2 to 3 mins, the mixture was shaken and incubated at room temperature for 30 mins. The absorbance was measured at $765 \mathrm{~nm}$ using a HACH DR/4000U spectrophotometer. TPCs were expressed as mg gallic acid equivalents in $g$ dry weight (mg GAE g ${ }^{-1} \mathrm{DW}$ ). TPCs in the organic extraction was calculated by water-soluble phenolics plus methanol-soluble phenolics.

Determination of Total Flavonoid Contents (TFCs)

Total flavonoid content was spectrophotometrically determined according to the $\mathrm{AlCl}_{3}$ method described by Djeridane et al. [19]. Briefly, $0.5 \mathrm{~mL}$ of extract was mixed with $0.5 \mathrm{~mL}$ of $2 \% \mathrm{AlCl}_{3}$ $(\mathrm{w} / \mathrm{v})$ in methanol. After a 15-minute incubation at room temperature, the absorbance was measured at $430 \mathrm{~nm}$ using a $\mathrm{HACH} \mathrm{DR} / 4000 \mathrm{U}$ spectrophotometer. TFCs were expressed as $\mathrm{mg}$ rutin equivalents in $\mathrm{g}$ dry weight ( $\mathrm{mg} \mathrm{RE} \mathrm{g}^{-1} \mathrm{DW}$ ). TFCs in the organic extraction were calculated by water-soluble flavonoids plus methanol-soluble flavonoids.

Determination of antioxidant capacity by DPPH assays

The radical-scavenging assay described by Elzaawely, Xuan, and Tawata [20] was used to determine the antioxidant capacity of five P. bivalvis samples. A volume of $0.5 \mathrm{~mL}$ extract was mixed with $0.25 \mathrm{~mL}$ of $0.5 \mathrm{mM}$ 2,2-diphenyl-1-picrylhydrazyl (DPPH) methanolic solution and 0.5 $\mathrm{mL}$ of $0.1 \mathrm{M}$ sodium acetate buffer $(\mathrm{pH}$ 5.5). After a slight shake, the mixture was incubated at room temperature for 30 mins without light exposure, followed by a measure at $517 \mathrm{~nm}$ using a HACH DR/4000U spectrophotometer. Radical scavenging activity was expressed as the inhibition percentage based on the following formula in Son and Lewis [21]:

$$
\% \text { radical scavenging activity }=\left[\left(\mathrm{A}_{\text {control }}-\mathrm{A}_{\text {sample }}\right) / \mathrm{A}_{\text {control }}\right] \times 100
$$

where $A_{\text {control }}$ is the absorbance of the control (DPPH solution without a sample, methanol instead) and $\mathrm{A}_{\text {sample }}$ is the absorbance of the P. bivalvis sample (DPPH solution plus extracts).

Statistical analysis

The analysis of data was conducted via ANOVA in the Minitab 16.0 software (Minitab Inc., State College, PA, USA). All experiments were carried out in triplicate and expressed as mean \pm standard error (SE). Significant differences among the means were compared using Turkey's test method with a confidential level of $95 \%$.

\section{Results}

Results of the ethnobotanical investigation in the northern mountainous region of Vietnam

Five villages in which two are in Lai Chau Province, one in Bac Kan Province and two in Thai Nguyen Province were selected as the fields for investigating the experience of using $P$. bivalvis for various purposes among local ethnic groups. Family members who are most accustomed to the use of $P$. bivalvis in each household are selected as respondents. As shown in Table 1, P1 and R varieties were commonly cultivated in Bac Kan and Thai Nguyen Province, while P3 and Y varieties could only be detected in Lai Chau Province, and P2 variety was sparsely cultivated in Thai Nguyen province. Most of the varieties were used by different cultural and ethnic groups for dyeing a number of traditional foods such as sticky rice and glutinous rice cakes serving in the special occasions. 
Table 1. Samples of Peristrophe bivalvis collected in September 2015, and ethnobotanical results concerning the local use of these plants in the northern Vietnam

\begin{tabular}{|c|c|c|c|c|}
\hline Variety & $\begin{array}{c}\text { Voucher/ } \\
\text { Abbreviation }\end{array}$ & $\begin{array}{c}\text { Distribution } \\
\text { location } \\
\text { Thai Nguyen and } \\
\text { Bac Kan province }\end{array}$ & Purple and black & $\begin{array}{c}\text { Food dye } \\
\text { and medicinal plant }\end{array}$ \\
\hline Purple P. bivalvis & $\mathrm{P} 2$ & $\begin{array}{c}\text { Thai Nguyen } \\
\text { province }\end{array}$ & Purple & Food dye \\
\hline Purple P. bivalvis & $\mathrm{P} 3$ & Lai Chau province & Purple & Food dye \\
\hline Red P. bivalvis & $\mathrm{R}$ & $\begin{array}{c}\text { Thai Nguyen and } \\
\text { Bac Kan province }\end{array}$ & Red and scarlet & $\begin{array}{c}\text { Food dye } \\
\text { and medicinal plant }\end{array}$ \\
\hline Yellow P. bivalvis & $\mathrm{Y}$ & Lai Chau province & Orange-yellow & Food dye (rarely) \\
\hline
\end{tabular}

The most commonly dyeing method used P. bivalvis was recorded as follows: the fresh stems and leaves were brought in boiling temperature with water for several minutes; the stems and leaves were then fished out of hot water decoction; after cooling, foodstuffs were soaked in that decoction to get the desired color. Most respondents said that one variety was used to dye a certain color; however, referring to the experience of Tay ethnic minority, P1 variety can generate both purple and black, and $\mathrm{R}$ variety can generate both red and scarlet. To get black color, an amount of straw ash was added into hot water decoction of P1 variety before soaking the foodstuff, whereas to get scarlet with R variety, vinegar or pineapple's leaves or Elaeagnus latifolia shoots were added into the decoction. Besides, P1 and R varieties were used as medicinal plants, which was introduced by two local healers in a village in Thai Nguyen Province. Accordingly, whole dried parts of P1 variety were mixed with some other herbs for the treatment of haemoptysis, dysentery, liver disease and kidney failure. In addition, the decoction of fresh leaves of $\mathrm{P} 1$ and $\mathrm{R}$ varieties was used to bath baby to cure jaundice. Nevertheless, the compounds and remedies remained covert because the healers believed that this would no longer be effective for treatment.

\section{Determination of plant pigments}

Total photosynthetic pigment contents

The differences of photosynthetic pigment contents are as illustrated in Table 2. While Chl $a$ presented a minute amount and no significant difference between varieties, Chl $b$ contents were significantly different among five $P$. bivalvis varieties. In particular, $\mathrm{R}$ variety exhibited the highest amount of $\mathrm{Chl} b$, followed by $\mathrm{P} 1$ variety, $\mathrm{P} 2$ variety, $\mathrm{P} 3$ variety, and $\mathrm{Y}$ variety. Total carotenoids were only expressed by $\mathrm{Y}$ variety.

Table 2. Total chlorophyll a, chlorophyll $\mathrm{b}$ and carotenoids ( $\left.\mathrm{mg} \mathrm{g}^{-1} \mathrm{DW}\right)$

\begin{tabular}{|c|r|r|r|r|r|}
\hline & \multicolumn{1}{|c|}{ P1 } & \multicolumn{1}{c|}{ P2 } & \multicolumn{1}{c|}{ P3 } & \multicolumn{1}{c|}{ R } & \multicolumn{1}{c|}{ Y } \\
\hline Chlorophyll a & $0.001 \pm 0.000$ & $0.001 \pm 0.000$ & $0.001 \pm 0.000$ & $0.001 \pm 0.000$ & $0.002 \pm 0.000$ \\
\hline Chlorophyll b & $0.584 \pm 0.012 \mathrm{~b}$ & $0.533 \pm 0.013 \mathrm{c}$ & $0.446 \pm 0.023 \mathrm{~d}$ & $0.633 \pm 0.017 \mathrm{a}$ & $0.222 \pm 0.002 \mathrm{e}$ \\
\hline Carotenoids & 0.000 & 0.000 & 0.000 & 0.000 & $0.025 \pm 0.001$ \\
\hline
\end{tabular}

Means that do not share a letter in the same row are significantly different $(P<0.05)$

\section{Total anthocyanin contents}

Anthocyanins of $P$. bivalvis varieties are shown in Table 3. Three out of six extracts indicated the results of TACs which were MWH, HW, and W50 extracts. For MWH extract, all varieties performed TACs except P2 variety, in which $\mathrm{R}$ variety showed the highest concentration which was tailed by $\mathrm{P} 3$ variety, $\mathrm{P} 1$ variety, and Y variety. On the other hand, only P2 variety exposed TACs in 
the HW extract. As for W50 extract, TACs were only presented by P1 and P2 varieties, of which TACs of P1 variety was higher than TACs of P2 variety.

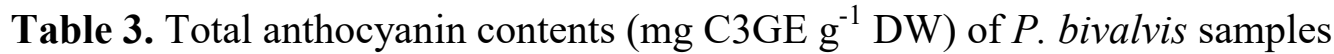

\begin{tabular}{|l|r|r|r|r|r|}
\hline \multirow{2}{*}{ Method } & \multicolumn{5}{|c|}{ TAC } \\
\cline { 2 - 6 } & \multicolumn{1}{|c|}{ P1 } & \multicolumn{1}{c|}{ P2 } & \multicolumn{1}{c|}{ P3 } & \multicolumn{1}{c|}{ R } \\
\hline MWH & $0.078 \pm 0.001 \mathrm{c}$ & 0.000 & $0.146 \pm 0.001 \mathrm{~b}$ & $0.244 \pm 0.003 \mathrm{a}$ & $0.055 \pm 0.002 \mathrm{~d}$ \\
\hline HW & 0.000 & $0.021 \pm 0.001$ & 0.000 & 0.000 & 0.000 \\
\hline W50 & $0.038 \pm 0.001 \mathrm{a}$ & $0.003 \pm 0.000 \mathrm{~b}$ & 0.000 & 0.000 & 0.000 \\
\hline
\end{tabular}

Means that do not share a letter in the same row are significantly different $(P<0.05)$

\section{Determination of total phenolic contents}

Effect of extraction methods used organic solvents on phenolic contents

There was a significant effect of extraction methods and dissolved solutions on phenolics of $P$. bivalvis varieties (Table 4). It is easy to see that the phenolics dissolved more strongly in water than in methanol. The highest mean of phenolics was obtained by $\mathrm{MH}$ extraction. Among five varieties, $\mathrm{Y}$ variety averaged the highest phenolic concentration, followed by $\mathrm{P} 3$ variety, $\mathrm{R}$ variety, $\mathrm{P} 1$ variety, and $\mathrm{P} 2$ variety.

\section{Total phenolic contents}

The total phenolics of $P$. bivalvis varieties are shown in Table 5. There were significant differences in TPCs among varieties in different extraction methods. The highest TPCs was observed in $\mathrm{MH}, \mathrm{MWH}$, and $\mathrm{HW}$ extracts. On average, Y variety experienced the highest TPCs in comparison with other varieties, of which Y variety presented the highest amount of TPCs in HW extract, whereas the lowest one was found in $\mathrm{R}$ variety in the same extract.

\section{Determination of total flavonoid contents}

Effect of extraction methods used organic solvents on flavonoid contents

The differences in flavonoid content between extracts used organic solvents are shown in Table 6. With the exception of $\mathrm{P} 1$ and $\mathrm{P} 2$ varieties in EWH and $\mathrm{MH}$ extract, most flavonoids of $P$. bivalvis samples dissolved more strongly in water than in methanol. In particular, P1 variety and P2 variety in EWH extract and $\mathrm{P} 2$ variety in $\mathrm{MH}$ extracts, all indicated the flavonoids concentration in methanolic solution higher than in water solution. The most prominent flavonoids content was showed in the MH extract. P3 variety contained the highest concentration of flavonoids, followed by $\mathrm{P} 1$ variety, $\mathrm{R}$ variety, $\mathrm{P} 2$ variety, and $\mathrm{Y}$ variety.

\section{Total flavonoid contents}

Total flavonoids of $P$. bivalvis varieties are described in Table 7. The TFCs were different among varieties in different extraction methods. The MH extract signified the highest TFC, in which the highest TFC was shown by P1 variety, the lowest one was shown in Y variety. On average, Y variety represented the lowest TFC, while P1, P2, P3, and R varieties showed the higher ones, respectively. 


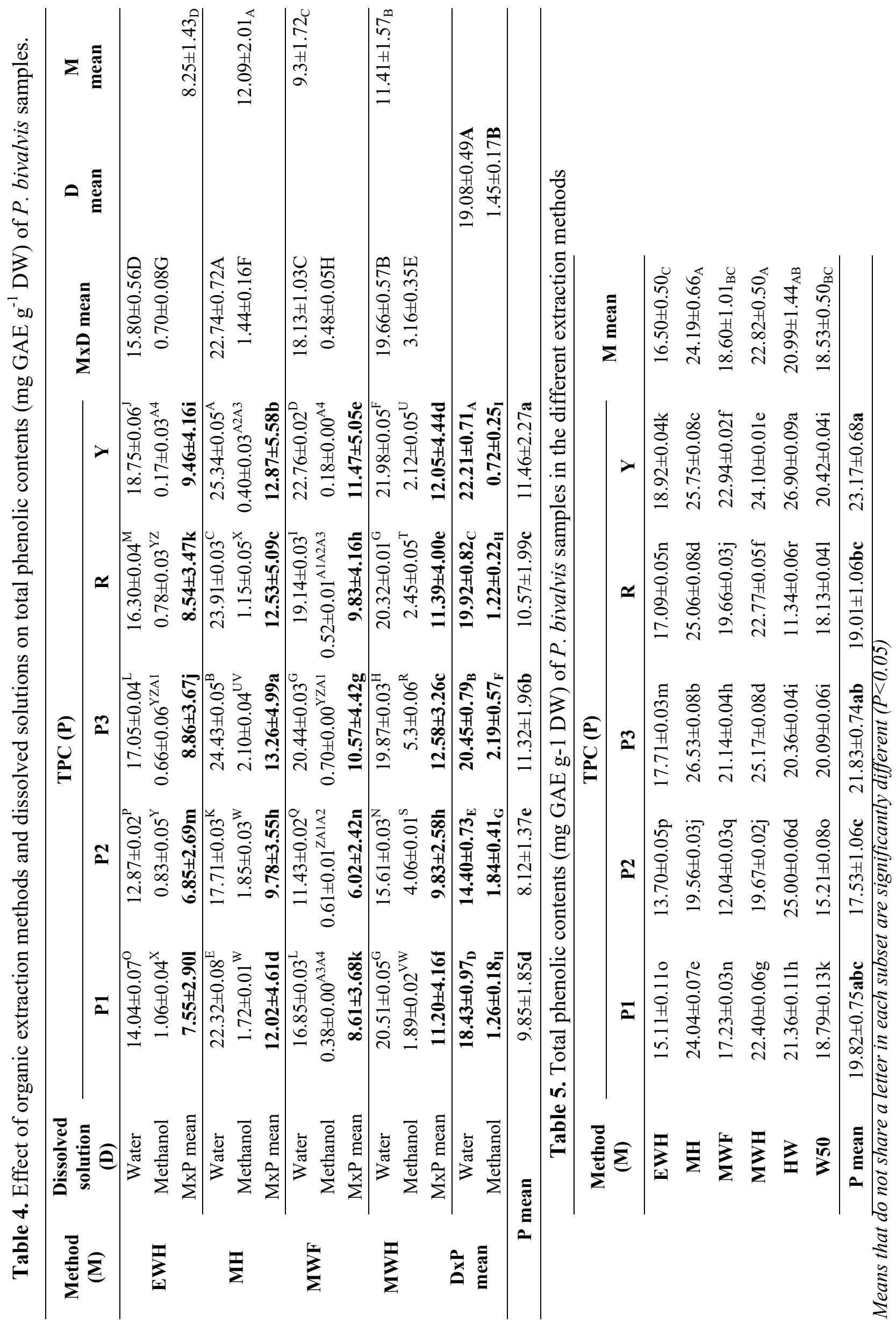




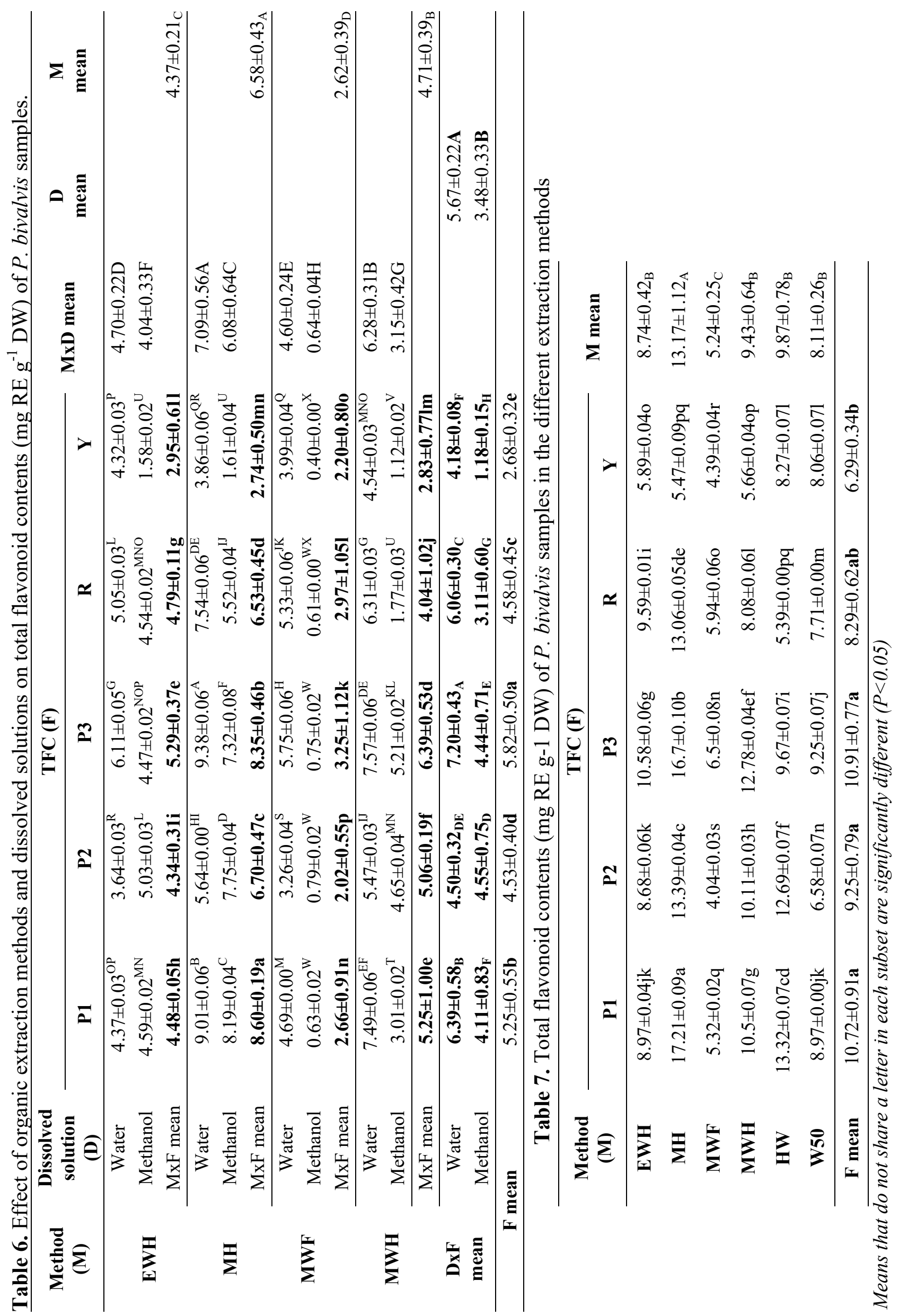




\section{Antioxidant capacity of Peristrophe bivalvis varieties}

The above results pointed that the solubility of anthocyanins, phenolics, and flavonoids of $P$. bivalvis samples were stronger in water than in methanol, which resulted in only the samples dissolving in aqueous solution were selected to test DPPH scavenging activity. Table 8 shows the inhibition percentages of $P$. bivalvis varieties in different extracts at a concentration which was ten times diluted by methanol from the original concentration. It can be seen that the DPPH radical scavenging capacity of each variety varied in extraction methods and differed from others. The extractions used organic solvents exhibited DPPH scavenging activity were higher than those used aqueous solvent. Particularly, most of the P. bivalvis varieties performed DPPH scavenging activities higher than 50\% in EWH, $\mathrm{MH}$, and $\mathrm{MWF}$ extracts, except $\mathrm{P} 2$ variety which showed a $36.35 \%$ radical inhibition in $\mathrm{MH}$ extract. For extractions by water, only Y variety in $\mathrm{HW}$ extracts exhibited the inhibition percentage higher than $50 \%$, meanwhile, the others showed the reverse.

Table 8. Inhibition percentages of aqueous extracts at a concentration, which were 10 times diluted by methanol from the original extracts.

\begin{tabular}{|c|c|c|c|c|c|c|}
\hline \multirow{2}{*}{$\begin{array}{l}\text { Method } \\
\text { (M) }\end{array}$} & \multicolumn{5}{|c|}{ Inhibition percentage $(\%)$} & \multirow{2}{*}{ M mean } \\
\hline & P1 & P2 & $\mathbf{P 3}$ & $\mathbf{R}$ & $\mathbf{Y}$ & \\
\hline EWH & $67.22 \pm 0.09 \mathrm{c}$ & $57.88 \pm 0.24 \mathrm{hi}$ & $59.8 \pm 0.09 \mathrm{f}$ & $58.79 \pm 0.28 \mathrm{~g}$ & $69.51 \pm 0.16 b$ & $62.64 \pm 1.28_{\mathrm{A}}$ \\
\hline MH & $60.73 \pm 0.09 \mathrm{e}$ & $36.35 \pm 0.09 p$ & $62.41 \pm 0.09 \mathrm{~d}$ & $58.6 \pm 0.09 \mathrm{gh}$ & $73.14 \pm 0.15 \mathrm{a}$ & $58.24 \pm 3.22_{\mathrm{AB}}$ \\
\hline MWF & $69.85 \pm 0.09 \mathrm{~b}$ & $48.87 \pm 0.09 \mathrm{k}$ & $69.39 \pm 0.18 \mathrm{~b}$ & $62.76 \pm 0.09 \mathrm{~d}$ & $69.48 \pm 0.00 \mathrm{~b}$ & $64.07 \pm 2.15_{\mathrm{A}}$ \\
\hline MWH & $43.57 \pm 0.19 n$ & $55.12 \pm 0.09 \mathrm{j}$ & $47.04 \pm 0.161$ & $45.54 \pm 0.09 \mathrm{~m}$ & $59.06 \pm 0.09 \mathrm{fg}$ & $50.07 \pm 1.6_{\mathrm{B}}$ \\
\hline HW & $12.97 \pm 0.17 \mathrm{t}$ & $26.03 \pm 0.10 \mathrm{r}$ & $47.17 \pm 0.101$ & $12.58 \pm 0.25 \mathrm{t}$ & $57.54 \pm 0.10 \mathrm{i}$ & $31.26 \pm 4.86_{\mathrm{C}}$ \\
\hline W50 & $42.73 \pm 0.17 \mathrm{o}$ & $23.16 \pm 0.26 \mathrm{~s}$ & $31.49 \pm 0.10 \mathrm{q}$ & $31.4 \pm 0.17 \mathrm{q}$ & $31.34 \pm 0.18 \mathrm{q}$ & $32.02 \pm 1.67_{\mathrm{C}}$ \\
\hline$\%$ mean & $49.51 \pm 4.72 \mathbf{a b}$ & $41.23 \pm 3.3 \mathbf{b}$ & $52.88 \pm 3.03 \mathbf{a b}$ & $44.95 \pm 4.35 \mathbf{b}$ & $60.01 \pm 3.4 \mathbf{a}$ & \\
\hline
\end{tabular}

Means that do not share a letter in each subset are significantly different $(P<0.05)$

\section{Discussions}

\section{Indigenous knowledge and diversity of Peristrophe bivalvis}

Indigenous knowledge has been seen as a treasure of accumulated knowledge and belief that are passed through many generations by transmitting the culture of the relationship between creatures including humans and their living environment [22]. The special relationship between indigenous knowledge and biodiversity are getting more and more attention recently [23, 24, 25], especially in the field of biodiversity conservation [1]. Vietnam, ranking $16^{\text {th }}$ among most biodiversity-rich countries in the world, prioritizes the preservation of cultural diversity as well as of indigenous knowledge in using natural resources (for example, plants) [26].

The results of current usage and experience in using $P$. bivalvis varieties of ethnic minorities in the North of Vietnam has contributed more information to the indigenous knowledge and biodiversity in Vietnam. Besides the popular uses in coloring food and other traditional products, $P$. bivalvis used as a folk remedy plays a role as the premise for further research in the field of pharmaceutical extracts and natural dye large-scale production. Especially, P3 variety was detected as a new member of $P$. bivalvis. The variety that is used the same way to get purple but has different morphological characteristics and biochemical components compared to the other previously described varieties. Although the experiment conducted on biochemical components partly indicated differences, it is still necessary to be provided more evidence from genotypic analysis to affirm whether the P3 variety is in the taxonomic tree or not.

\section{Phytochemical contents in Peristrophe bivalvis varieties}

The colors in higher plants are basically assigned by pigments which are very diverse in structure and classification of which photosynthetic pigments and flavonoids are considered as the main groups contributing colorful countenance of plant. In particular, chlorophylls with the largest presence of $\mathrm{Chl} a$ and $\mathrm{Chl} b$ in plant cells are responsible for green color; while carotenoids are for red, orange or yellow which also play as accessory pigments in photosynthesis [27]. Meanwhile, 
flavonoids, a group of secondary metabolites, have the widest color range from pale-yellow to blue, in which, anthocyanins, a class of flavonoids, take their color from the range of red, purple, or blue, depending on their $\mathrm{pH}$ [28] and are sensitive to temperature and light [29]. By spectral analysis, Thuy et al. [9] isolated the major component of the color aqueous extract of red P. bivalvis leaves which was so-called peristrophine. In this study, the color extract components of $P$. bivalvis varieties were also identified as photosynthetic pigments and anthocyanins.

As shown in Table 2, Chl $a$ shows a negligible quantity which can be explained by using a dried sample for measurement. The degradation of chlorophylls was reviewed in many studies related to leaf senescence [30,31] and loss of moisture in leaves [32]. In the same situation, the degradation of carotenoids in P. bivalvis samples might be elucidated by the effect of drying and storage [33,34] In summary, the photosynthetic pigments of $P$. bivalvis are certainly involved in the color formation of samples' extracts. Chlorophyll $b$ occupied a positive amount in coloration of $P$. bivalvis varieties. The yellow-orange extract of $\mathrm{Y}$ variety is defined in part by carotenoids. Dried samples are not suitable to determine components of photosynthetic pigments in P. bivalvis.

Anthocyanins are water-soluble pigments and commonly extracted by acidified solvents like water, ethanol, alcohol or aqueous solvents [35,36]. By using spectrophotometric determination, the best result of anthocyanin contents was certified in MWH extract which most $P$. bivalvis varieties shared anthocyanin values, except P2 variety (Table 3). However, P2 variety presented a molar amount of anthocyanins in HW and W50 extract. Especially, the anthocyanins value of P2 variety treated by $100^{\circ} \mathrm{C}$ was higher than that by $50^{\circ} \mathrm{C}$. It proved that the anthocyanins of $\mathrm{P} 2$ variety might be linked with some compounds that keep it more enduring in high temperature. Therefore, the unique absence in organic extracts and only presence in water extracts of anthocyanin in P2 variety may be explained by the effect of temperature and extraction solvent. In addition, only R variety presented methanol-soluble anthocyanins $\left(3.70 \mathrm{mg} \mathrm{C} 3 \mathrm{GE} \mathrm{g}^{-1}\right.$ which was not shown in Table 3$)$ in MWH extract, that is to say, methanol-soluble anthocyanins can be an indicator to identify and differentiate the $\mathrm{R}$ variety from other varieties.

Also, the differences in color can be clarified by referring to the flavonoid contents results (Table 6 , Table 7). Accordingly, the average of water-soluble flavonoids was mostly higher than methanolsoluble flavonoids, meaning the water-soluble flavonoids as anthocyanins play an important role in coloration of $P$. bivalvis. Moreover, the significant differences in total flavonoid contents among five varieties can be used as an indicator [37] for P. bivalvis classification.

In summary, the coloration components of Peristrophe bivalvis varieties were contributed by a complex compound of photosynthetic pigments, anthocyanins, and flavonoids. Additionally, the determination of coloration components of $P$. bivalvis varieties was influenced by many factors such as drying condition, temperature, and type of extraction solvents.

\section{Antioxidant capacity of Peristrophe bivalvis extracts}

Antioxidants have a crucial role in neutralizing free radical species inducing DNA degradation, cell damage and physical and mental disorders. Thus, they are supposed to be capable of protecting human against infections and degenerative diseases due to the ability to prevent the deleterious consequences of oxidative stress [38]. Plants certainly contain a rich source of natural antioxidants. A plenty of previous studies reported flavonoids (flavones, flavanones, isoflavones, flavonols, flavanonols, flavan-3-ols, anthocyanins and anthocyanidins) and phenolic compounds (derivatives of benzoic acid such as gallic acid, and derivatives of cinnamic acid such as coumaric, caffeic and ferulic acid) are the major groups of natural antioxidants which can help plant to cope with stresses and diseases [39-43]. Naturally, phenolic compounds produced in plants as secondary metabolites [44], and its concentrations not only heavily depend on species, but it is also affected by extraction methods and solvents. Several studies have proven that the antioxidant activity correlated with total phenolic compounds [45]. In this study, total phenolic contents of P. bivalvis samples (Y, P1, and P3) were found to follow the similar trend of DPPH radical scavenging activity. Therefore, this result confirmed that phenolic compounds contained in the extracts strongly influence antioxidant activity. Moreover, most of the organic extracts showed the antioxidant activity greater than $50 \%$. This could simply be explained that the solvents, such as methanol, ethanol, acetone, ethyl acetate, 
and their combinations are more productive in phenolics isolation from plant materials than water [38]. It is generally known that the antioxidant activity is not only affected by solvents alone, but it is also influenced by extraction time and temperature. However, the DPPH scavenging activity of $P$. bivalvis extracts was low in $100^{\circ} \mathrm{C}$ and $50^{\circ} \mathrm{C}$ water extractions. Obviously, high temperature probably causes phenolic oxidation, and consequently reduces its biological activity [41].

\section{Conclusions}

The indigenous knowledge in using Peristrophe bivalvis varieties of ethnic minorities plays an important role in researches on biodiversity and conservation of plant resource in Northern Vietnam in particular and in Vietnam in general. Apart from previous described P. bivalvis varieties, the discovery of P3 variety contributes to the diversity at the sub-species level or variety level of the species, which has received much attention recently. The results of phytochemicals determination and evaluation of antioxidant activity do not only support the classification of Peristrophe bivalvis but also can be informative in many fields, such as the production of natural dyes and pharmaceutical preparations from Peristrophe bivalvis through selecting the most appropriate extraction solvent.

\section{Acknowledgement}

The authors are thankful to the Graduate School for International Development and Cooperation (IDEC) - Hiroshima University for providing necessary facilities to carry out the study. Special thanks are also extended to Thai Nguyen University of Agriculture and Forestry -Vietnam for the supports during the field survey in Vietnam.

\section{References}

[1] Convention on Biological Diversity. (n.d.). Article 8. In-situ Conservation. Retrieved on December 15, 2015, from https://www.cbd.int/convention/articles/default.shtml?a=cbd-08.

[2] V.V. Chi, (A Dictionary of Vietnamese Medicinal Plant), Tu dien Cay thuoc Vietnam. Medicine Publication, Vietnam, pp. 191, 1999. (In Vietnamese).

[3] L.N. Trinh et al., Agrobiodiversity conservation and development in Vietnamese home gardens, Agr. Ecosyst. Environ. 97(1-3) (2003) 317-344.

[4] N.T.P. Thao et al., Study on Peristrophe bivalvis (L.) Merr. in Muong Khuong district, Lao Cai province. In 3rd National Scientific Conference on Ecology and Biological Resources. Hanoi: IEBR (2009).

[5] W. Yang, F. Gu, J. Lü, M. Yang, Effect of the extract from Peristrophe roxburghiana on hemorheology in rats, Zhong Yao Cai. 25(10) (2002) 727-728.

[6] Z. Cheng, J. Lü, J. Liu, Effects of Peritrophe roxburghiana on blood pressure in renal hypertensive and hyperlipidemic rats, Zhong Yao Cai. 27(12) (2004) 927-930.

[7] R. K. Verma, L. Chaurasia, S. Katiyar, Potential antifungal plants for controlling building fungi, Indian J. Nat. Pro. Res. 7(4) (2008) 374-387.

[8] C. Wiart et al., Antimicrobial screening of plants used for traditional medicine in the state of Perak, Peninsular Malaysia, Fitoterapia. 75(1) (2004) 68-73.

[9] J. Phaopongthai et al., Biological activities of Peristrophe bivalvis extracts: Promising potential for anti-snake venoms against Naja kaouthia and Trimeresurus albolabris venoms, Nat. Pro. Res. 30(6) (2015) 697-699.

[10] S.S. Tanavade, N.S. Naikwade, D.D. Chougule, Antimicrobial activity of ethanolic extracts of leaves and stems of Peristrophe bivalvis Merrill, Int. J. Biome. Res. 2 (2012) 106-108.

[11] S.S. Tanavade, N.S. Naikwade, D.D. Chougule, In vitro anticancer activity of ethanolic and aqueous extracts of Peristrophe bivalvis Merrill, Res. J. Phar. Techno. 5(10) (2012) 1324-1327. 
[12]T.T. Thuy et al., Isolation, characterisation and biological evaluation of a phenoxazine, a natural dyestuff isolated from leaves of Peristrophe bivalvis, Nat. Pro. Res. 27(8) (2013) 771774.

[13]T.T. Thuy et al., Natural phenoxazine alkaloids from Peristrophe bivalvis (L.) Merr., Biochem. Sys. Ecol. 44 (2012) 205-207.

[14]H. Metzner, H. Rau, H. Senger, Studies on Synchronization of Some Pigment-deficient Chlorella Mutants, Planta. 65(2) (1965) 186-194. (In German with English abstract).

[15]K.A. Fayez, S.A. Bazaid, Improving drought and salinity tolerance in barley by application of salicylic acid and potassium nitrate, J. Saudi Soci. Agric. Scien. 13(1) (2014) 45-55.

[16]M.M. Giusti, L.E. Rodriguez-Saona, R.E. Wrolstad, Molar absorptivity and color characteristics of acylated and non-acylated pelargonidin-based anthocyanins, J. Agric. Food Chem. 47(11) (1999) 4631-4637.

[17]J. Lee, R.W. Durst, R.E. Wrolstad, Determination of total monomeric anthocyanin pigment content of fruit juices, beverages, natural colorants, and wines by the $\mathrm{pH}$ differential method: collaborative study, J. AOAC Int. 88(5) (2005) 1269-1278.

[18]A.A. Elzaawely, T.D. Xuan, H. Koyama, S. Tawata, Antioxidant activity and contents of essential oil and phenolic compounds in flowers and seeds of Alpinia zerumbet (Pers.) B.L. Burtt. \& R.M. Sm, Food Chem. 104(4) (2007) 1648-1653.

[19]A. Djeridane et al., Antioxidant activity of some Algerian medicinal plants extracts containing phenolic compounds, Food Chem. 97(4) (2006) 654-660.

[20]A.A. Elzaawely, T.D. Xuan, S. Tawata, Antioxidant and antibacterial activities of Rumex japonicus Houtt aerial parts, Biol. Pharm. Bull. 28(12) (2005) 2225-2230.

[21]S. Son, B.A. Lewis, Free Radical Scavenging and Antioxidative Activity of Caffeic Acid Amide and Ester Analogues: Structure-Activity Relationship. J. Agric. Food Chem. 50 (2002) 468-472.

[22]F. Berkes, Traditional ecological knowledge in perspective, in: J.T. Inglis (Ed.), Traditional Ecological Knowledge - Concepts and Cases, IDRC, Ottawa, Canada, 1993, pp. 1-9.

[23] M. Gadgil, F. Berkes, C. Folke, Indigenous Knowledge for Biodiversity Conservation, Ambio. 22(2/3) (1993) 151-156.

[24]M. Cocks, Biocultural Diversity: Moving Beyond the Realm of 'Indigenous' and 'Local' People, Human Ecol. 34(2) (2006) 185-200.

[25] J. Pretty et al. The Intersections of Biological Diversity and Cultural Diversity: Towards Integration, Conservation and Society. 7(2) (2009) 100-112.

[26]J.S. de Queiroz, D. Griswold, N.D. Tu, P. Hall, Vietnam Tropical Forest and Biodiversity Assessment, Sun Mountain International and the Cadmus Group, Inc, pp. vii (2013). Retrieved from

https://www.usaid.gov/sites/default/files/documents/1861/Vietnam118_119FinalDraft\%2015O ct2013\%20(Public\%20Version).pdf.

[27]Photosynthetic Pigments. Ucmp.berkeley.edu. Retrieved 2 April 2016, from http://www.ucmp.berkeley.edu/glossary/gloss3/pigments.html.

[28] Y. Tanaka, N. Sasaki, A. Ohmiya, Biosynthesis of plant pigments: anthocyanins, betalains and carotenoids, The Plant J. 54(4) (2008) 733-749.

[29]I. Rabino, A.L. Mancinelli, Light, temperature, and anthocyanin production, Plant Physiol. 81(3) (1986) 922-924.

[30]S. Hörtensteiner, B. Kräutler, Chlorophyll breakdown in higher plants, Biochimica Et Biophysica Acta (BBA) - Bioenergetics. 1807(8) (2011) 977-988.

[31]N.A. Eckardt, A new chlorophyll degradation pathway, The Plant Cell. 21(3) (2009) 700.

[32]M. Salete et al., Effect of harvesting and drying conditions on chlorophyll levels of soybean (Glycine max L. Merr.), J. Agric. Food Chem. 51(6) (2003) 1634-1639.

[33]F.W. Quackenbush, Corn carotenoids: Effects of temperature and moisture on losses during storage, Cereal Chem. 40 (1963) 266-268. 
[34]A. Bechoff et al., Effect of drying and storage on the degradation of total carotenoids in orangefleshed sweetpotato cultivars, J Sci. Food Agric. 90(4) (2010) 622-629.

[35]G. Patil, M.C. Madhusudhan, B.R. Babu, K.S.M.S Raghavarao, Extraction, dealcoholization and concentration of anthocyanin from red radish, Chem. Eng. Process. 48(1) (2009) 364-369.

[36]J.M. Kong et al., Analysis and biological activities of anthocyanins, Phytochem. 64(5) (2003) 923-933.

[37]G. Dudek et al., A spectrophotometric method for plant pigments determination and herbs classification, Chem. Papers. 68(5) (2014) 579-583.

[38] S. Sreelatha, P.R. Padma, Antioxidant activity and total phenolic content of Moringa oleifera Leaves in Two Stages of Maturity, Plant Foods Hum. Nutr. 64(4) (2009) 303-311.

[39] M.P. Kahkonen et al., Antioxidant defense system in vegetable extracts, in: F. Shahidi (Ed.), Natural Antioxidants: Chemistry, Health Effects, and Applications, AOCS Press: Champaign, IL, US, 1997, pp. 76-87.

[40] O. Çaliskan, A.A. Polat, Phytochemical and antioxidant properties of selected fig (Ficus carica L.) accessions from the eastern Mediterranean region of Turkey, Sci. Hortic. 128(4) (2011) 473-478.

[41]J. Dai, R.J. Mumper, Plant phenolics: extraction, analysis and their antioxidant and anticancer properties, Molecules. 15(10) (2010) 7313-7352.

[42]P.G. Pietta, Flavonoids as antioxidants, J. Nat. Prod. 63(7) (2000) 1035-1042.

[43]C.A. Rice-Evans et al., The relative antioxidant activities of plant derived polyphenolic flavonoids, Free Rad. Res. 22(4) (1995) 375-383.

[44]D.M. Kasote, S.S. Katyare, M.V. Hegde, H. Bae, Significance of Antioxidant Potential of Plants and its Relevance to Therapeutic Applications, Int. J. Biol. Sci. 11(8) (2015) 982-991.

[45]Y. Hong, S. Lin, Y. Jiang, M. Ashraf, Variation in contents of total phenolics and flavonoids and antioxidant activities in the leaves of 11 Eriobotrya species, Plant food Hum Nutr. 63 (2008) 200-204. 